\title{
ASSESSING THE FEASIBILITY OF USING BUILDING INFORMATION MODELLING (BIM) TO IMPROVE COLLABORATION ON PUBLIC SECTOR PROJECTS IN THE ZAMBIAN CONSTRUCTION INDUSTRY
}

\author{
DANSTAN BWALYA CHIPONDE, LAWRENCE PUNDA MUTALE, \\ JOSEPHINE M. ZIKO \& NDONDO JALO \\ Department of Construction Economics and Management, Copperbelt University, Zambia
}

\begin{abstract}
This study was conducted in order to improve collaboration on public sector projects in the Zambian Construction Industry (ZCI) through the application of Building Information Modelling (BIM). In order to meet the research objectives, a questionnaire survey was used in collecting data and an exploratory research approach was adopted. Both quantitative and qualitative methods for data collection and analysis were also used. Worth noting as a limitation of this research is that only 64 questionnaires from the 111 that were distributed were received and this may not be representative of the ZCI. Further, only 2 provinces out the 10 in the country were considered for data collection. The findings revealed that the common collaboration challenges faced on public projects include delays in information exchange, poor project relationship and information management. This was mainly due to the huge reliance on $2 \mathrm{D}$ documents as a means of information exchange and the traditional procurement method. Hence, in order to eliminate collaboration challenges, the use of BIM is inevitable in the ZCI because it promotes efficient communication and coordination among project parties. This is important because construction projects involve the exchange of information among the many stakeholders involved. Therefore, if construction professionals are to attain their goals, this will require that new collaborative means are adopted, essentially adopting BIM in the ZCI and world over.

Keywords: collaboration, Building Information Modelling, public projects, Zambian construction industry.
\end{abstract}

\section{INTRODUCTION}

The construction industry involves a huge exchange of information amongst its many stakeholders who are in different locations such as drawings, specifications, and conditions of the contract which are important for the successful completion of any construction undertaking. This has been necessitated by the increase in complexity and size of construction projects [1]-[3]. Therefore, a collaborative environment of multidisciplinary professionals is an important factor for success [2]. However, this is not the case in the Zambian Construction Industry (ZCI) and world over because communication on many projects remains a challenge and leads to time and cost overruns [4], [5]. In the ZCI evidently Mukuka et al. [4] note that the traditional system of managing building projects has created room for delays in exchange of information, due to poor collaborative practices it uses leading to cost and time overruns. This is due to the fragmentation of the teams which allows information wastage [6], [7]. Therefore, a more collaborative approach to information management is needed. On the other hand, Building Information Modelling (BIM) and its collaborative management capabilities have been identified as potential solutions to managing project information [8]. Collaboration through BIM has since been seen to solve construction challenges related the fragmentation of the construction industry in countries such as the UK, Finland and Norway as a way of meeting project objectives such as cost certainty and increased productivity [9], [10]. Therefore, in order for the 
Zambian government to achieve value on public works it should embrace the use of BIM on public construction projects realising that huge sums of money are spent annually on the provision of public infrastructure from limited resources. Therefore, this research was undertaken to assess the feasibility of using BIM in improving collaboration on public sector projects thereby enhancing projects delivery.

\section{THE ZCI AND COLLABORATION CHALLENGES ON PUBLIC PROJECTS}

The construction industry is considered as one of the key factors in economic development and sustained strength world over including in Zambia. Further, public procurement is estimated to account for between 10 and $15 \%$ of GDP and in Zambia, this is estimated at $10 \%$ of GDP [11], [12]. This is through the provision of public infrastructure such as roads, housing and health and education facilities. Hence, the procurement of public infrastructure must be done in an efficient manner realizing that governments have limited resources. To achieve this, the Zambian government engages public sector organisations in infrastructure delivery such as; National Housing Authority (NHA), Road Development Agency (RDA), local government authorities and other quasi government organisations. The key parties that are involved in the delivery of such infrastructure are the client who could be a government agency, local authorities or a ministry. All these organisations mainly receive funding from the government to finance their projects. Consultants who consist of architects, engineers (civil, structural, and electrical) and quantity surveyors are also involved. The other party is a contractor who manages the construction process [11]-[13]. On the other hand, the ZCI has not escaped the challenges facing other countries in delivering projects such as poor quality, delay and cost overruns which are linked to the huge reliance on the traditional project delivery method [4]-[14]. This is even when new methods such as design and build have been introduced [15]. The method has also been known to have other shortfalls such as low levels of collaboration on a project leading to difficulties in communication [4], [6], [16]. Kaliba et al. [17] further argue that since inefficiencies such as delays of construction projects are prevalent in the ZCI, there is a need to improve the project delivery process in order to meet the project objectives. Wei [18] identified site management, supervision and communication as some of the means through which project delivery can be improved. Mukuka et al. [4] also noted that collaborative working is one aspect that can be applied in trying to improve project delivery in the ZCI. Further, BIM has been used by other countries such as the UK as a solution to providing a collaborative working environment on projects [10]. Thus, if the ZCI is to improve collaboration and consequently improve project delivery, it is imperative that BIM is adopted by the industry practitioners.

\section{COLLABORATION AND BIM}

Collaboration has become an important input on any project due to the fact that construction projects involve a complex number of relationships which need to interact and exchange volumes of information if projects are to be successful [16]. Baker [19] defines collaboration as a means of shared understanding through interaction with others, were the participants are committed to or engaged on shared goals and problem solving. Essentially, it involves the process of sharing information and resources through mutual engagement of participants in order to meet the set goals [20]. Further, with many project parties not being in one location, it has become apparent that sharing of knowledge and information is one of the key elements of a successful project since it enhances coordination and communication [1]. Therefore, collaboration has become an important aspect of construction projects since it creates a platform for enhanced knowledge sharing and communication amongst the 
many project participants. This leads to improved problem solving and resourcing unlike in situations only one individual or organisation is involved [19], [21].

\subsection{Project collaboration benefits of using BIM}

BIM has been identified as a tool that can be used to improve the collaboration process [10]-[22]. Succar [23] defines it as a set of interacting policies, processes and technologies generating a methodology to manage the essential building design and project data in digital format. Notably, BIM does not only consider the application of software but also incorporates project management. It also has a potential for use during construction of a structure in improving collaboration between stakeholders [8]-[24]. This reduces the time needed for documentation of the project, hence, leading to the achievement of project objectives [1]. This is due to the use of technology to produce 3D models which help to eliminate challenges that may be faced in the actual construction works and helps in making decisions on the physical and functional aspects of a building by giving 4D and 5D for cost and time modelling respectively [22], [24], [25]. Essentially, BIM is used in collaboration through the following ways:

- Sharing Design Content - BIM provides easy and more secure information exchange with control through the use of software such as Software as a Service (SaaS) [26].

- Project Coordination - BIM-supported software helps bring about effective coordination on projects by integrating multidiscipline models allowing visualization, review and coordination [26].

Consequently, data modelling, BIM, according to Autodesk [26] enhances collaboration due to the following:

- A model facilitates information capture and exchange of various systems [25].

- It provides data management solutions that can securely store and effectively distribute project information across the lifecycle of a project [25].

- Promotes delivering information across the project lifecycle to any one at any time it is needed without restriction to location [1]-[26].

It has also been noted that with BIM, collaboration is enhanced through the use of models which increase the response rate to change orders and request for information on a project by $40 \%$ resulting in reduced overall project duration of $7 \%$ [24]. Unarguably, collaboration cannot be achieved on a project unless effective coordination and effective communication is made [5]. Therefore, with the noted challenges that the ZCI is experiencing with respect to collaboration, BIM presents itself as the means through which collaboration can be enhanced. This is by creating a data management system and creation of, $4 \mathrm{D} / 5 \mathrm{D}$ construction simulations allowing detection of clash, missing information which enhances collaboration [25]. However, its application is not always met with ease. These include start up costs, information control, copyrights, industry's culture and resistance, conditions of contract and lack of software interoperability [1]-[22]. Therefore, it is important that would-be applicants in the ZCI pay particular attention to challenges that have been noted.

\section{RESEARCH METHODOLOGY}

This research adopted an exploratory approach since it tried to gain knowledge on a subject matter in order to make a conclusion. This was in relation to BIM being applied in the ZCI 
as a means of improving collaboration. Both qualitative and quantitative data research methods were applied in order to reinforce the limitations of each method [27], [28].

\subsection{Sampling method and sample sizes}

The data was collected from Lusaka and Copperbelt provinces of Zambia because these have a high presence of construction activities than other provinces. The sample size included clients (6) and consultants (39) who were sampled using the judgemental sampling method. The consultants comprised of architects (17), quantity surveyors (10) and civil engineers (12). A total number of 66 contractors were also selected and since they have sub-groupings stratified sampling method was used. Further, due to the limited number of construction works in the ZCI, the industry practitioners participate in both private and public works. Hence the target group comprised of those who have undertaken both private and public works. Thus, a total of 111 questionnaires were distributed and 64 were retained giving a response rate of $58 \%$.

\subsection{Data collection tools and analysis}

A survey and structured self administered questionnaires were used to collect data on collaboration on public projects and BIM can be used in enhancing it. This is owing to the fact that the survey is an economical means of collecting data from a population. Questionnaires are also considered to be cheaper and can reach easily respondents in different locations [27]. The Relative Importance Index (RII) was used in considering factors leading to poor collaboration on public sector projects. Microsoft excel was also used in the presentation of the findings in tables.

\section{RESEARCH FINDINGS AND DISCUSSION}

The following are the main findings from the data that was collected.

\subsection{Most used procurement route}

The findings indicated that Design-Bid-Build (D-B-B) system is the most frequently used method (86.1\%). Design and Build was the second (8.3\%) while PPP and others accounted for $5.6 \%$. This is line with other findings which indicate that the ZCI mainly uses the traditional procurement methods [14]. Thus, it is evident that the challenges in collaboration that are associated with the fragmentation of the industry are a common feature in the ZCI which needs immediate attention.

\subsection{Challenges faced with projects}

The $1^{\text {st }}$ and highest ranked challenge by both contractors and consultants; with RII of 0.85 and 0.945 respectively from Table 1 is insufficient information in design data. On the other hand, consultant ranked $2^{\text {nd }}$ misinterpretation of design specification by contractors who ranked it the least $\left(6^{\text {th }}\right)$. This clearly shows that there is a challenge with how the industry manages construction information. Notably contractors ranked management of information and delays in information exchange as $2^{\text {nd }}$ and $3^{\text {rd }}$ respectively which further illustrates the fact that collaboration is highly impacted by the poor management of information. Unforeseen mistakes and discrepancies and poor project relationship and communication were ranked by the contractor as $4^{\text {th }}$ and $5^{\text {th }}$ respectively while the consultants ranked them $3^{\text {rd }}$ and $6^{\text {th }}$ respectively. From Table 1 it can thus be observed that these challenges that 
contractors and consultants experience on projects affects collaboration among project parties as noted by other scholars [4]. Many of these challenges are hinged upon the huge reliance on the traditional method which has a fragmented team and this continues to hinder smooth delivery of projects in the ZCI just like in other countries. This therefore leads to insufficient information in design documents, poor project team relationships and communication [6], [7] [29], [30]. On the other hand, BIM offers solutions to overcome most of the above problems since technology is used in the storage and management data on a project [8]. Hence challenges faced by the ZCI during collaboration such as insufficient information in design data can be noticed earlier by having a BIM system in place.

\subsection{Format of information exchange}

The majority of the respondents indicated that communicating of information is done through hardcopy. This is based on the findings, which indicated that the soft copies accounted for $5.6 \%$, while hardcopies accounted for $41.4 \%$, and a combination of both at $53 \%$ occasionally. The respondents also cite the e-mail as a tool of exchanging information in soft copy format. Therefore, two dimensional (2D) drawings are predominately used on projects as a communication medium among project members in the ZCI.

\subsubsection{Types of software used and their efficiency - architects and civil engineers}

Amongst the architects, AutoCard (100\%) was the most used followed by Microsoft office $(88 \%)$. Revit $(63 \%)$ was $3^{\text {rd }}$ while ArchiCard was $4^{\text {th }}(29 \%)$ and Atlantis $(1 \%)$ was the least followed by Lumion (2\%). Amongst the engineers, Autocad and Microsoft packages were the most used at 100\% followed by AutoDesk civil at 90\%. Other software such as Bentley, Buzzsaw and Navisworks were not used at all by both architects and engineers. Further, rating these tools on how efficient they are in collaboration, $21 \%$ indicated that they are efficient and $47 \%$ and $32 \%$ indicated not efficient and quite efficient respectively. Essentially this shows that the industry has appreciated the use of software in document management but not widely practiced and it still remains with challenges in this regard. However, the software being used currently also set a basis on which BIM can start being applied in the ZCI.

Table 1: Challenges faced by contractors and consultant in during collaboration.

\begin{tabular}{|l|r|r|r|r|r|r|}
\hline Challenges & \multicolumn{3}{|l|}{ Contractor } & \multicolumn{3}{l|}{ Consultants } \\
\hline & RII & $\%$ & Ranking & RII & $\%$ & Ranking \\
\hline $\begin{array}{l}\text { Insufficient information in } \\
\text { design contents }\end{array}$ & 0.850 & $85.0 \%$ & $1^{\text {st }}$ & 0.945 & $94.5 \%$ & $1^{\text {st }}$ \\
\hline Management of information & 0.826 & $82.6 \%$ & $2^{\text {nd }}$ & 0.757 & $75.7 \%$ & $4^{\text {th }}$ \\
\hline Delays in information exchange & 0.820 & $82.0 \%$ & $3^{\text {rd }}$ & 0.747 & $74.7 \%$ & $5^{\text {th }}$ \\
\hline $\begin{array}{l}\text { Poor project relationship and } \\
\text { communication }\end{array}$ & 0.820 & $82.0 \%$ & $4^{\text {th }}$ & 0.817 & $81.7 \%$ & $3^{\text {rd }}$ \\
\hline $\begin{array}{l}\text { Unforeseen mistakes and } \\
\text { discrepancies }\end{array}$ & 0.800 & $80.0 \%$ & $5^{\text {th }}$ & 0.600 & $60.0 \%$ & $6^{\text {th }}$ \\
\hline $\begin{array}{l}\text { Misinterpretation of } \\
\text { design/specifications by } \\
\text { contractor }\end{array}$ & 0.780 & $78.0 \%$ & $6^{\text {th }}$ & 0.826 & $82.6 \%$ & $2^{\text {nd }}$ \\
\hline
\end{tabular}




\subsection{Types of software used and their efficiency - quantity surveyors}

Amongst the quantity surveyors (QSs), the most used software was the Microsoft package at $100 \%$ used for preparation of programs, cashflow projections and bill of quantities. This was followed by AutoCAD 75\% since in some instances drawings in AutoCAD format are given to them which offers a 3D view of the buildings. The least used was WinQs at $25 \%$ followed by Revit Architecture at 38\%. This clearly shows that there is a low use of new tools especially among QSs realizing that even the introduction of estimating packages such as WinQS, its use is still low. With respect to efficiency of these methods in collaboration, $28 \%$ indicated efficient while $72 \%$ indicated inefficient. This clearly shows that the industry has challenges in sharing and managing information. Hence, instead of relying on excel and other traditional software, BIM must be encouraged especially among QS since it offers an opportunity to reduce costs through the use of $4 \mathrm{D}$ and $5 \mathrm{D}$, time and cost modelling [22].

\subsection{Most willing to collaborate}

The contractor was ranked the highest at $45 \%$. Architects and quantity surveyors were ranked $20 \%$ the least being engineers at $15 \%$. Such results have been propelled by relying on the traditional procurement method which maintains separate teams. This is due to the fact that majority of designers (consulting engineers and architects) still operate in isolation and only pass the works to each other through the traditional procurement method. Hence to improve collaboration, it is imperative that the ZCI adopts other procurement methods that promote integration and collaboration among team members such as design and build and integrated project delivery (IPD).

\subsection{Making changes to documentation}

$61 \%$ indicated that making changes to project documentation was inefficient while $39 \%$ found the process efficient. This can be linked to the format, majority being hard copy, in which information is exchanged and managed among project members. Introducing BIM will therefore help to overcome this challenge since it enables project parties to make and track all changes. This is important realising that during construction variations always occur and revisions have to be made and communicated quick enough [10]-[24].

\subsection{Knowledge and experience of BIM in the ZCI}

From the contractors' responses, 69.5\% were not knowledgeable on BIM whilst $19.4 \%$ was found to have basic knowledgeable on BIM whilst a population of $11.1 \%$ was found to be very knowledgeable among contractors. On the other hand, consultants as compared to contractors $60 \%$ of the population had basic knowledgeable about BIM whilst $28 \%$ were knowledgeable with $12 \%$ not being knowledgeable. From the findings, majority of the respondents' knowledge on BIM was found to be very low. Further considering the distribution of the level of industry experience of the respondents, majority $(41.7 \%)$ in the industry had more than 15 years' experience while $30.6 \%$ had 5-10 years. $22.2 \%$ had 10-15 years of experience, with 5.5\% comprising those with less than 5 years' experience none of these categories have ever experienced or used BIM before, besides having the knowledge. This shows that for a long period there has been a slow intake of new approaches in the construction process in the ZCI especially with the use of Information Technology (IT) as evidenced by the low levels of knowledge on BIM. 


\subsection{Improving collaboration in the ZCI using BIM}

$48 \%$ of the respondents strongly agreed that BIM can improve collaboration in the ZCI, of which $36 \%$ agreed and $12 \%$ merely disagreed. Only $4 \%$ of the respondents strongly disagreed. From the findings, a substantial number agree that the use of BIM and its associated software and system will enhance collaboration realizing that the current means of communication and exchange of information are limited due to a huge reliance on hardcopy and 2D documents.

\subsection{Challenges of BIM implementation}

All (100\%) of the respondents agreed that cost of software was a major challenge of BIM adoption. $100 \%$ of both the clients and contractors and $90 \%$ of consultants also indicated that lack of knowledge on BIM will also be a challenge. Since there is low level of knowledge on BIM, shortage of skill in BIM training was another impediment to its implementation with both contractors and consultant indicating $90 \%$ while the client's $95 \%$. On the other hand, all the respondents disagreed that reluctance from practitioners to adopt BIM would be a challenge. Hence there is keen interest in adopting BIM in the ZCI realizing that the challenges earlier highlighted that can be solved by its application. Respondents had no problems with adopting software's, as long as it is readily accessible and cost effective on eliminating inefficiencies faced in the industry. However, some of these challenges highlighted above, including resistance from the industry and culture, are what have been experienced in other countries where BIM has been applied [1]-[22]. Hence, if its application is to see meaningful results in the ZCI, it is important that the above challenges are eliminated or mitigated.

\section{CONCLUSIONS AND RECOMMENDATIONS}

Collaboration in the ZCI remains a challenge and in many circumstances has lead to poor delivery of projects. This has been linked to the huge reliance on the traditional procurement method which has been known to have limitations. Further the use of software in the industry has been low especially among consulting quantity surveyors. Further, the most common format of exchanging documents is through hard copies. This has resulted in inefficiency during the construction process since documents cannot be shared faster or any changes made easily. However, BIM has been known to enhance the collaboration process through the use of models that aid in making informed decisions from the design through construction and occupation of a building [1]-[22]. Hence if the ZCI is to improve its collaboration process, it is crucial that BIM is adopted by those participating on public funded projects realizing that huge sums of money are spent on such projects and yet cost and time overruns are a common feature. This is important because BIM will not only improve the management of information or collaboration but also reduce the time and cost overruns on project and further improve relationships of the project team members [22]-[24]. This is due to the fact that the inherent nature of BIM and use of models allows eliminating project challenges, detecting errors in the documents and creates an environment of sharing of resources. However, its application will prove a challenge due to the fact that the knowledge on BIM in the ZCI is very low and many cited the cost of acquiring software and IT tools a major hindrance. Therefore, it will be of the essence for the industry to build on the knowledge of BIM by making it a part of training programmes for Architecture, Construction and Engineering (ACE) students and conduct seminars and workshops for the industry practitioners. 


\section{REFERENCES}

[1] Arayici, Y., Egbu, C. \& Coates, P., Building information modelling (BIM) implementation and remote construction projects. Issues, challenges and critiques. Journal of Information Technology in Construction (ITcon), 17, pp. 75-92, 2012. http://www.itcon.org/2012/5. Accessed on: 12 Feb. 2017.

[2] Coates, P., Arayici, Y., Koskela, L., Kagioglou, M., Usher, C. \& O’Reilly, K., The limitations of BIM in the architectural process. First International Conference on Sustainable Urbanism, December 2010, Hong Kong, 2010.

[3] Wang, Y., How to facilitate information exchange process in BIM-related international construction project, MSc thesis, University of Twente, Enschede, Netherlands, 2014.

[4] Mukuka, M., Aigbavboa, C. \& Thwala, W., Remedies to timely delivery of construction projects in Lusaka, Zambia - an exploratory study. Journal of Construction Project Management and Innovation, 4(1), pp. 906-911, 2014.

[5] Latham, M., Constructing the team. Final report of the government/industry review of procurement and contractual arrangements in the UK construction industry, HMSO, London, 1994.

[6] Egan, J., Rethinking construction: The report of the Construction Task Force. London: HM Stationery Office, 1998.

[7] Demian, P. \& Walters, D., The advantages of information management through building information modelling. Construction Management and Economics, pp. 1-13, 2014.

[8] Jordani, D., BIM: A healthy disruption to a fragmented and broken process. Journal of Building Information Modelling: Spring 2008, Matrix Group Publishing: Houston, TX, 2008.

[9] McAuley, B., Hore, A. \& West, R., Implementing building information modelling in public works projects in Ireland. Proceedings of the 9th European Conference on Product and Process Modelling, 25-27 Jul. 2012, Reykjavik, Ireland, 2012.

[10] Bataw, A., Kirkham, R. \& Lou, E., The issues and considerations associated with BIM integration. MTEC Web of Conferences, 66, 00005, 2016.

[11] World Bank, Zambia public expenditure tracking and quality of service delivery survey in the health sector. Findings and implications, 2007.

[12] Zambia Development Agency, Zambia Development Agency Annual Report 2014.

[13] Odhiambo, W. \& Kamau, P., Public procurement: Lessons from Kenya, Tanzania and Uganda, Working Paper No. 208, OECD Development Centre, 2003.

[14] Mukumbwa, B. \& Muya, A., Ethics in the construction industry in Zambia. The International Journal of Construction Management, 13(2), pp. 43-65, 2013.

[15] Friedlander, M.C., Construction project delivery methods: Which is best for you? Illinois State Bar Association (ISBA), 1(1), 2011.

[16] Illeneuve, C.E. \& Fayek, A.R., Construction project websites: Design and implementation. Cost Engineering, 45(1), pp. 26-36, 2003.

[17] Kaliba, C., Muya, M. \& Mumba, K., Cost escalation and schedule delays in road construction projects in Zambia. International Journal of Project Management, 27, pp. 522-531, 2009.

[18] Wei, S.K., Causes, effects and methods of minimizing delays in construction projects, Universiti Teknologi, Malaysia, 2010.

[19] Baker, M., Forms of cooperation in dyadic problem-solving. Cooperation and Complexity, eds P. Salembier \& H. Benchekroun, 16(1), pp. 587-620, 2002. 
[20] Rahmana, S.H.A., Enduta, I.R., Faisola, N. \& Paydard, S., The importance of collaboration in construction industry from contractors' perspectives. Proceedings of International Conference on Innovation, Management and Technology Research, 22-23 Sep., Malaysia, 2013.

[21] Keast, R., Brown, K. \& Mandell, M., Getting the right mix: Unpacking integration meanings and strategies. International Public Management Journal, 10(1), pp. 9-33, 2007.

[22] Stanley, R. \& Thurnell, D., The benefits of, and barriers to, implementation of 5D BIM for quantity surveying in New Zealand. Australasian Journal of Construction Economics and Building, 14(1), pp. 105-117, 2014.

[23] Succar, B., Building information modelling framework: A research and delivery foundation for industry stakeholders. Automation in Construction, 18(3), pp. 357-375, 2009.

[24] Barrett, S., Spillane, J.P. \& Lim, J.B.P., Early implementation of building information modeling into a cold-formed steel company: Providing novel project management techniques and solutions to industry. American Journal of Civil Engineering and Architecture, 1(6), pp. 164-173, 2013. DOI: 10.12691/ajcea-1-6-6.

[25] Eastman, C., Teicholz, P., Sacks, R. \& Liston, K., BIM Handbook: A Guide to Building Information Modelling for Owners, Managers, Designers, Engineers, and Contractors, John Wiley \& Sons Inc.: NJ, 2008.

[26] Autodesk, I., Education success story Autodesk, University of Minnesota, 2002.

[27] Saunders, M., Lewis, P. \& Thornhill, A., Research Method for Business Students, 5th ed., Rotolito Lombarda Press: Italy, 2009.

[28] Kothari, C.R., Research Methodology Methods \& Techniques, New Age International: New Delhi, pp. 8-55, 2004.

[29] Kong, A.T. \& Gray, J., Problems with traditional procurement in the Malaysian construction industry; a survey, School of Urban Development, Queensland University of Technology, Sydney, 2006.

[30] Othman, A.A.E., Improving building performance through integrating constructability in the design process. Otmcj: An International Journal, 3(2), 2011. 